\title{
"Brain-Doping," Is It a Real Threat?
}

\author{
Darías Holgado ${ }^{1,2 *}$, Miguel A. Vadillo ${ }^{3}$ and Daniel Sanabria ${ }^{2 *}$ \\ ${ }^{1}$ Department of Physical Education and Sport, Faculty of Sport Sciences, University of Granada, Granada, Spain, \\ ${ }^{2}$ Department of Experimental Psychology, Mind, Brain and Behavior Research Centre, University of Granada, Granada, \\ Spain, ${ }^{3}$ Department of Basic Psychology, Autonomous University of Madrid, Madrid, Spain
}

Keywords: brain stimulation, exercise performance, doping, tDCS - transcranial direct current stimulation, meta-analaysis, sports performance

\section{OPEN ACCESS}

Edited by:

Giovanni Messina,

University of Foggia, Italy

Reviewed by:

Davide Viggiano,

University of Molise, Italy

*Correspondence:

Darías Holgado

dariashn@ugr.es

Danie/ Sanabria

danie/@ugr.es

Specialty section:

This article was submitted to

Exercise Physiology,

a section of the journal

Frontiers in Physiology

Received: 02 February 2019

Accepted: 08 April 2019

Published: 24 April 2019

Citation:

Holgado $D$, Vadillo $M A$ and Sanabria D (2019) "Brain-Doping," Is it a Real Threat? Front. Physiol. 10:483. doi: 10.3389/fphys.2019.00483
Since the term "Neurodoping" was introduced (Davis, 2013; Reardon, 2016), the use of transcranial direct current stimulation (tDCS) has gained popularity in Sports Science within a short space of time, based on the same straightforward logic: if exercise is to some extent determined by brain activity, then stimulating brain areas related to exercise should improve physical and sport performance. In fact, companies like Halo Sport claim that their "do-it-yourself" tDCS device has ergogenic effects and can increase sport and exercise performance (Reardon, 2016). In a recent review in Frontiers in Physiology, Angius et al. (2017) suggested that tDCS might have a positive effect on exercise capacity, although the mechanisms of that potential benefit were unknown. However, the expectations derived from those initial studies showing tDCS as an effective technique to increase exercise performance or reduce rate of perceived exertion (RPE), have left room for many others that do not seem to support the effectiveness of tDCS in the Sports science.

Indeed, recent meta-analyses have challenged the idea that tDCS can increase exercise performance or reduce RPE, mood or pain related to exercise (Holgado et al., 2018; Lattari et al., 2018a; Machado et al., 2018). For instance, based on the analysis of 36 effect sizes, Holgado et al. (2018)showed that the effect (if any) of tDCS on exercise performance is rather small $(g=0.34)$ and possibly inflated by methodological artifacts and selective publication. Similarly, the results of Machado et al. (2018) support the conclusion that tDCS has no effect on measures of muscle strength, although it may have a positive effect on cycling exercise. However, even this positive result seems to be entirely dependent on a single, low-quality study. Therefore, both Holgado et al. (2018) and Machado et al. (2018) reached the same conclusion: tDCS has little or no-effect on exercise performance. Moreover, it is worth mentioning that the chances of a publication bias in this topic are particularly high, that is, many other studies with null findings may not have been published or even sent for review (Holgado et al., 2018). So far, only one meta-analysis (Lattari et al., 2018a) has concluded that tDCS may be useful to increase performance. However, upon closer inspection, these results also seem to be grossly influenced by individual studies with unusually large effect sizes ( $g=3.56$ for Cogiamanian et al., 2007 and $g=1.94$ for Lattari et al., 2018b), casting doubts on the reliability of these effects. 
TABLE 1 | The most common placement of the tDCS' electrodes in the Sport Science research and its rationale.

\begin{tabular}{|c|c|}
\hline $\begin{array}{l}\text { Electrode } \\
\text { placement }\end{array}$ & Rationale \\
\hline $\begin{array}{l}\text { Primary motor } \\
\text { cortex (M1) }\end{array}$ & $\begin{array}{l}\text { Increase M1 excitability to speed neural drive to active muscles } \\
\text { Modulate pain perception }\end{array}$ \\
\hline $\begin{array}{l}\text { Prefrontal } \\
\text { cortex }\end{array}$ & $\begin{array}{l}\text { Changes in pacing behavior via executive functions, for } \\
\text { example, by increasing inhibitory control capacity }\end{array}$ \\
\hline $\begin{array}{l}\text { Temporal } \\
\text { cortex }\end{array}$ & $\begin{array}{l}\text { Modulate the activity of the insular cortex } \\
\text { Autonomic cardiac control } \\
\text { Changes in self-perception and awareness of body sensations }\end{array}$ \\
\hline $\begin{array}{l}\text { Supplementary } \\
\text { motor area }\end{array}$ & Reduce perceived exertion during exercise \\
\hline
\end{tabular}

The site of stimulation (Table 1), the fitness level of participants, the overly low sample sizes (average $N=15$; which may lead to overestimation of effect sizes) and the likely ineffectiveness of the usual stimulation intensity (1-2 mA; cf. Vöröslakos et al., 2018) are key issues that would need to be considered in future research. Regarding stimulation intensity, recent studies have proposed that due to the high inter-individual variability in participants' electric fields, it seems that the most efficient approach to induce constable cortical changes would be to apply an individualized current intensity for each person (Esmaeilpour et al., 2018; Laakso et al., 2019). Indeed, the usual stimulation intensity does not seem to induce oscillatory brain electrical changes at rest or during exercise (e.g., Holgado et al., 2019; cf. Vöröslakos et al., 2018). Finally, the sham

\section{REFERENCES}

Angius, L., Hopker, J., and Mauger, A. R. (2017). The ergogenic effects of transcranial direct current stimulation on exercise performance. Front. Psychol. 8:90. doi: 10.3389/fphys.2017.00090

Cogiamanian, F., Marceglia, S., Ardolino, G., Barbieri, S., and Priori, A. (2007). Improved isometric force endurance after transcranial direct current stimulation over the human motor cortical areas. Eur. J. Neurosci. 26, 242-249. doi: 10.1111/j.1460-9568.2007.05633.x

Davis, N. J. (2013). Neurodoping: brain stimulation as a performance-enhancing measure. Sports Med. 43, 649-653. doi: 10.1007/s40279-013-0027-Z

Esmaeilpour, Z., Marangolo, P., Hampstead, B. M., Bestmann, S., Galletta, E., Knotkova, H., et al. (2018). Incomplete evidence that increasing current intensity of tDCS boosts outcomes. Brain Stimul. Basic Transl. Clin. Res. Neuromodulation 11, 310-321. doi: 10.1016/j.brs.2017.12.002

Fonteneau, C., Mondino, M., Arns, M., Baeken, C., Bikson, M., Brunoni, A. R., et al. (2019). Sham tDCS: a hidden source of variability? Reflections for further blinded, controlled trials. Brain Stimul. doi: 10.1016/j.brs.2018.12.977. [Epub ahead of print].

Holgado, D., Vadillo, M. A., and Sanabria, D. (2018). The effects of transcranial direct current stimulation on objective and subjective indexes of exercise performance: a systematic review and meta-analysis. Brain Stimul. 12, 242-250. doi: 10.1016/j.brs.2018.12.002

Holgado, D., Zandonai, T., Ciria, L. F., Zabala, M., Hopker, J., and Sanabria, D. (2019). Transcranial direct current stimulation (tDCS) over the left prefrontal cortex does not affect time-trial self-paced cycling performance: evidence from oscillatory brain activity and power output. PLOS ONE 14:e0210873. doi: 10.1371/journal.pone.0210873

Laakso, I., Mikkonen, M., Koyama, S., Hirata, A., and Tanaka, S. (2019). Can electric fields explain inter-individual variability in transcranial direct current stimulation of the motor cortex? Sci. Rep. 9:626. doi: 10.1038/s41598-018-37226-x procedure might provide an additional source of variability, since without the appropriate procedure sham stimulation might have biological effects (Fonteneau et al., 2019).

In our opinion, the current evidence does not support the effectiveness of tDCS devices in the sport domain. It is therefore premature to make claims regarding the ergogenic benefits of tDCS and/or its potential thread as a novel doping tool. We believe, however, that this line of scientific enquiry could provide valuable knowledge if researchers endorse sound scientific practices (e.g., pre-registration, testing larger sample, multi-lab replications, etc.), to tackle issues like the role of stimulation intensity, the site of stimulation, and the interindividual variability.

\section{AUTHOR CONTRIBUTIONS}

All authors listed have made a substantial, direct and intellectual contribution to the work, and approved it for publication.

\section{FUNDING}

DS is awarded with a grant PSI2016-75956-P from Ministerio de Economía, Industria y Competitividad. DH is awarded with a grant FPU14/06229 from Ministerio de Educación, Cultura y Deporte. MV is awarded with grants 2016-T1/SOC-1395, from Comunidad de Madrid (Programa de Atracción de Talento Investigador, 2016) and PSI2017-85159-P from Ministerio de Ciencia, Innovación y Universidades. The funders are not involved directly in the preparation of this manuscript.

Lattari, E., Oliveira, B. R. R., Júnior, R. S. M., Neto, S. R. M., Oliveira, A. J., Neto, G. A. M., et al. (2018a). Acute effects of single dose transcranial direct current stimulation on muscle strength: A systematic review and meta-analysis. PLoS ONE 13:e0209513. doi: 10.1371/journal.pone.02 09513

Lattari, E., Rosa Filho, B. J., Fonseca Junior, S. J., Murillo-Rodriguez, E., Rocha, N., Machado, S., et al. (2018b). Effects on volume load and ratings of perceived exertion in individuals advanced weight-training after transcranial direct current stimulation. J. Strength Cond. Res. doi: 10.1519/JSC.0000000000 002434. [Epub ahead of print].

Machado, D. G. D. S., Unal, G., Andrade, S. M., Moreira, A., Altimari, L. R., Brunoni, A. R., et al. (2018). Effect of transcranial direct current stimulation on exercise performance: a systematic review and meta-analysis. Brain Stimul. doi: 10.1016/j.brs.2018.12.227. [Epub ahead of print].

Reardon, S. (2016). 'Brain doping' may improve athletes' performance. Nat. News 531, 283. doi: 10.1038/nature.2016.19534

Vöröslakos, M., Takeuchi, Y., Brinyiczki, K., Zombori, T., Oliva, A., Fernández-Ruiz, A., et al. (2018). Direct effects of transcranial electric stimulation on brain circuits in rats and humans. Nat. Commun. 9, 1-17. doi: 10.1038/s41467-018-02928-3

Conflict of Interest Statement: The authors declare that the research was conducted in the absence of any commercial or financial relationships that could be construed as a potential conflict of interest.

Copyright (C) 2019 Holgado, Vadillo and Sanabria. This is an open-access article distributed under the terms of the Creative Commons Attribution License (CC BY). The use, distribution or reproduction in other forums is permitted, provided the original author(s) and the copyright owner(s) are credited and that the original publication in this journal is cited, in accordance with accepted academic practice. No use, distribution or reproduction is permitted which does not comply with these terms. 